\title{
Análise temporal de Cyanobacteria e Índice de Estado Trófico na PCH Porto Franco, Tocantins
}

\author{
Anelise Kappes MARQUES ${ }^{[1 ; *]}$; Dayane Juliate BARROS ${ }^{[1]}$ e Paula Benevides MORAIS ${ }^{[2]}$ \\ ${ }^{[1]}$ Universidade Federal do Tocantins, Campus Palmas. Laboratório de Microbiologia Ambiental e Biotecnologia. Avenida NS 15, 109 Norte - Plano \\ Diretor Norte, 77001-090. Palmas-TO, Brasil. Email: dayjuliat@ gmail.com \\ ${ }^{[2]}$ Professora do programa de Pós-Graduação Doutorado em Biodiversidade e Biotecnologia da Amazônia Legal (BIONORTE). Laboratório de \\ Microbiologia Ambiental e Biotecnologia. Avenida NS 15, 109 Norte - Plano Diretor Norte, 77001-090. Palmas-TO, Brasil. E-mail: \\ moraispb@uft.edu.br
}

\begin{tabular}{|c|c|}
\hline INFORMAÇÕES & RESUMO \\
\hline Recebido em: 01/09/2015 & \multirow{11}{*}{$\begin{array}{l}\text { As cianobactérias são componentes naturais do fitoplâncton e têm recebido uma } \\
\text { atenção da comunidade científica e dos órgãos ambientais por desenvolverem } \\
\text { florações em ambientes com condições eutróficas. O Índice de Estado Trófico (IET) é } \\
\text { um diagnóstico da saúde do corpo hídrico em relação ao seu grau de trofia. Este } \\
\text { trabalho teve como objetivo avaliar a qualidade da água no reservatório da PCH Porto } \\
\text { Franco através da abundância relativa de Cyanobacteria e o IET. Foram realizadas } 19 \\
\text { coletas no período de } 2009 \text { a } 2014 \text { onde se avaliou em quatro pontos amostrais a } \\
\text { comunidade fitoplanctônica, fósforo e clorofila a. As cianobactérias ocorreram em } \\
\text { todos os pontos monitorados e foram representadas por vários táxons potencialmente } \\
\text { tóxicos, como Cylindrospermopsis raciborski e Planktolyngbya limnetica. Esses } \\
\text { organismos são potencialmente tóxicos e podem provocar danos à saúde humana e ao } \\
\text { ambiente. A dominância de Cyanobacteria está associada às condições mesotróficas a } \\
\text { supereutróficas que ocorreram principalmente no ponto a montante barramento. O } \\
\text { predomínio do ambiente lêntico, disponibilidade de radiação subaquática, bem como a } \\
\text { alta concentração de nutrientes demonstrados pelo IET são condições que determinam } \\
\text { o expressivo desenvolvimento de Cyanobacteria neste reservatório. }\end{array}$} \\
\hline Aceito em: $20 / 11 / 2015$ & \\
\hline Publicado em: 23/12/2015 & \\
\hline Document Object Identifier & \\
\hline 10.18067/jbfs.v2i4.57 & \\
\hline Termos de indexação: & \\
\hline eutrofização & \\
\hline qualidade da água & \\
\hline bioindicadores & \\
\hline *Autor para correspondência & \\
\hline & \\
\hline
\end{tabular}

\section{Temporal analysis of Cyanobacteria and Trophic State Index in PCH Porto Franco (Tocantin's State,} North Brazil)

ABSTRACT- Cyanobacteria are typical phytoplankton components and they have received attention from the scientific community due to develop blooms in eutrophic environments. The Trophic State Index (TSI) is diagnosis of water body's condition due to trophic level. This work aimed to estimate water quality from PCH Porto Franco reservoir based on Cyanobacteria abundance and TSI. During the period of 2009 to 2014, 19 sampling were performed in four points in which were analyzed the phytoplankton community, phosphorus and chlorophyll $a$. Cyanobacteria were detected in all the monitored points and exhibit potentially toxic taxa, for instance, Cylindrospermopsis raciborski and Planktolyngbya limnetica. These organisms are substantially toxic and may provoke harm to human health and to the environment. The Cyanobacteria dominance is associated with mesotrophic to hypereutrophic conditions, which have occurred mainly in upstream barriers. The predominance of a lentic environment, underwater radiation availability and high nutrient concentration demonstrated by TSI are conditions that determine the significantly development of Cyanobacteria in this reservoir.

Index terms: eutrophication, water quality, bioindicators

Copyright: (c) 2015 JBFS all rights. This is an open-access article distributed under the terms of the Creative Commons Attribution License, which permits unrestricted use, distribution, and reproduction in any medium, provided the original author and source are credited.

Financiamento: Os autores reportam que houve suporte e auxílio financeiro pela Fundação de Apoio Científico e Tecnológico do Tocantins (Convênio 314).

Conflito de interesse: Os autores declaram que não há conflito de interesse.

Como referir esse documento (ABNT):

MARQUES, A. K.; BARROS, D. J.; MORAIS, P. B. Análise temporal de Cyanobacteria e Índice de Estado Trófico na PCH Porto Franco, Tocantins. Journal of Bioenergy and Food Science, Macapá, v.2, n.4, p.137-144, out./dez., 2015. http://dx.doi.org/10.18067/jbfs.v2i3.57

\section{INTRODUÇÃO}

As Pequenas Centrais Hidrelétricas (PCHs) são empreendimentos hidrelétricos com potência instalada até 30MW que representam uma forma rápida e eficiente de expansão da oferta de energia elétrica, sendo importante fonte de energia 
renovável [1]. Sua implantação envolve a construção de barramentos e formação de reservatórios.

A qualidade da água e consequente eutrofização dos reservatórios está relacionada com os vários usos múltiplos das bacias hidrográficas: irrigação, ausência de tratamento de esgotos nas cidades com consequente lançamento de efluentes os cursos de rios, atividade de pecuária e atividades agrícolas [2]. Essa crescente degradação dos recursos hídricos pelo enriquecimento de nutrientes, especialmente nitrogênio e fósforo, produz profundas modificações qualitativas e quantitativas nas comunidades aquáticas, nas condições físicas e químicas do meio, tornando a água imprópria ao consumo humano, e aumentando a incidência de florações de microalgas e cianobactérias [3].

Cianobactérias são organismos procariotos fotossintetizantes, cosmopolitas, que podem ser encontrados em vários ambientes no planeta, sendo muito comuns no plâncton de reservatórios. Estruturalmente se assemelham as bactérias, podendo ser unicelulares, coloniais e filamentosas. A capacidade de crescimento nos mais diferentes meios é uma das características relevantes das cianobactérias. $\mathrm{O}$ enriquecimento por nutrientes dos corpos hídricos cria condições favoráveis ao estabelecimento destes micro-organismos que podem formar florações [4].

O Índice do Estado Trófico (IET) possui como objetivo a classificação de corpos d'água em diferentes graus de trofia, partindo do levantamento das concentrações do nutriente limitante (fósforo) e da clorofila "a" [5]. O IET pode ser considerado como um registro das atividades humanas nas várias bacias hidrográficas, além de fornecer subsídios para a formulação de planos de manejo e gestão de ecossistemas aquáticos, por meio de estratégias que visem à sustentabilidade dos recursos hídricos e que garantam os usos múltiplos da água, em médio e longo prazo [6].

Assim, torna-se necessário o conhecimento
da representatividade das cianobactérias planctônicas, organismos bioindicadores da qualidade da água e que se desenvolvem nos reservatórios para que medidas mais efetivas possam ser tomadas, sendo extremamente escassos os trabalhos com este objetivo. Diante da importância ecológica e sanitária das cianobactérias e da insuficiência de dados mais detalhados sobre sua relação com a qualidade da água, o presente trabalho teve como objetivo avaliar a qualidade da água no reservatório da $\mathrm{PCH}$ Porto Franco através da abundância relativa de Cyanobacteria e o IET.

\section{MATERIAL E MÉTODOS}

A PCH Porto Franco, localizada no rio Palmeiras, abaixo da PCH Diacal, ocupa áreas pertencentes aos municípios de Dianópolis pela margem direita e de Novo Jardim pela margem esquerda. As obras foram iniciadas em agosto de 2006 com término em agosto de 2009. O início do enchimento do reservatório da PCH Porto Franco ocorreu em maio de 2009, com finalização do enchimento total em agosto de 2009, com o uma área total de $5,6 \mathrm{~km}^{2}$. O rio Palmeiras, desde a década de noventa, vem sendo objeto de estudos buscando o aproveitamento do seu potencial hidrelétrico. Entretanto, somente em 2002 a Agência Nacional de Energia Elétrica aprovou a construção de PCHs em seu leito. A PCH Porto Franco está localizada na área de influência considerada Complexo Hidrelétrico Palmeiras [7]. Atualmente é um ambiente destinado a produção de energia elétrica e aquicultura compondo um sistema de reservatórios em cascata.

Foram realizadas 19 coletas, a partir do enchimento do reservatório, no período de julho 2009 a junho de 2014, onde se avaliou em quatro pontos amostrais a comunidade fitoplanctônica, fósforo e clorofila a. O ponto 01 está localizado a montante do reservatório na área de transição entre o sistema lótico e lêntico, o ponto 02 na parte central do reservatório, em frente ao barramento se encontra o ponto 03 e o ponto 04 está a jusante da barragem (Figura 1).

Figura 1. Pontos de coleta no reservatório da $\mathrm{PCH}$ - Porto Franco.

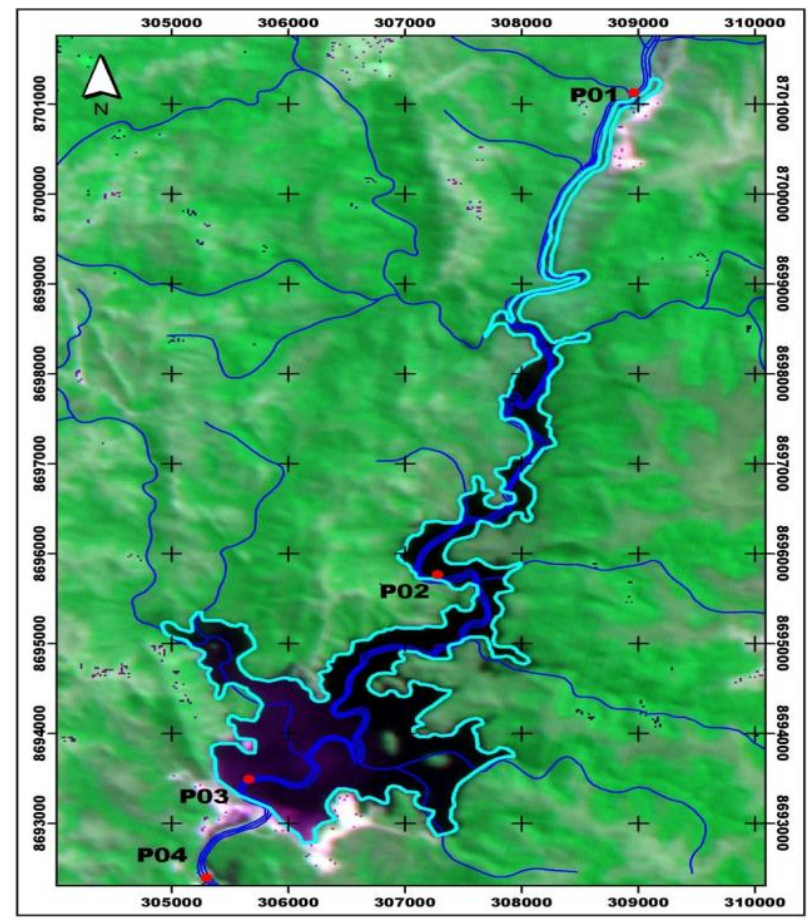

Fonte: Elaborado pelo autor 
Amostras quali-quantitativas de fitoplâncton foram coletadas na subsuperfície dos pontos amostrais por meio de rede de plâncton $25 \mu \mathrm{m}$ e recolhimento de 1 litro de água bruta. As amostras para estudos qualitativos foram fixadas com solução de Transeau (1:1), analisadas em microscópio óptico OLYMPUS BX41 e aquelas para análise quantitativa com lugol acético com concentração final a $1 \%$ [8]. A densidade do fitoplâncton foi estimada pelo método de Utermöhl [9] a partir de campos aleatórios através de quantificação de organismos (células, colônias, cenóbios e filamentos) em microscópio ZEISS PRIMOVERT a 400 aumentos, e expressa em ind. $\mathrm{mL}^{-1}$. As contagens foram feitas após cerca de 3 horas de sedimentação para cada centímetro de altura da câmara. A quantificação dos organismos foi efetuada até estabilizar o número de espécies adicionadas por campo (área de compensação) ou até atingir 100 indivíduos da espécie mais frequente. De acordo com Lund [10], deste modo, o erro da contagem será inferior a $20 \%$, nível de significância 95\%. As espécies dominantes e abundantes foram definidas segundo Lobo e Leighton [11]. A abundância relativa de Cyanobacteria apresentada nos resultados é referente à porcentagem que este grupo representa no fitoplâncton total e foi calculada de forma a demonstrar percentualmente o quanto cada táxon é presente dentro da amostra [12].

As análises de clorofila $a$ e fósforo total seguiram metodologia preconizada no Standard Methods for the Examination of Water and Wastewater [9] e tiveram suas concentracões mensuradas em espectrofotômetro (HACH DR 5000). Para a análise de clorofila $a$, as amostras foram agitadas vigorosamente e uma alíquota de $250 \mathrm{ml}$ foram filtradas através de uma bomba de vácuo, usando filtro analítico em microfibra de vidro de $47 \mathrm{~mm}$ de diâmetro. Os filtros utilizados foram deixados, por um período de quatro horas, em uma solução de Clorofórmio-Metanol (2:1) [13] (Wood, 1985). Posteriormente, a leitura da clorofila $a$ foi feita em espectrofotômetro (HACH DR 5000), com comprimentos de onda de $665 \mathrm{~nm}$ e $750 \mathrm{~nm}$.

O Índice do Estado Trófico é composto pelo Índice do Estado Trófico para o fósforo - IET (PT) e o Índice do Estado Trófico para a clorofila a - IET (CL), modificados por Lamparelli [14] e estabelecidos para ambientes lênticos conforme as equações:

$\operatorname{IET}(C L)=10 x(6-((0,92-0,34 x(\ln C L)) / \ln 2)) \quad$ Eq. (1)

$\operatorname{IET}(\mathrm{PT})=10 \mathrm{x}(6-(1,77-0,42 \mathrm{x}(\ln \mathrm{PT}) / \ln 2))$
Onde: PT é a concentração de fósforo total medida à superfície da água, em $\mu$ g. $\mathrm{L}^{-1}$; CL é a concentração de clorofila a medida à superfície da água, em $\mu \mathrm{g} . \mathrm{L}^{-1}$; ln é o logaritmo natural

Os limites estabelecidos para as diferentes classes de trofia para rios são: ultraoligotrófico (IET $\leq 47)$, oligotrófico $(47<\mathrm{IET} \leq 52)$, mesotrófico $(52<\quad$ IET $\leq 59)$, eutrófico $(59<\quad$ IET $\leq 63)$, supereutrófico $(63<$ IET $\leq 67)$ e hipereutrófico (IET> 67). O IET final foi à média aritmética simples dos índices anuais relativos ao fósforo total e a clorofila a.

\section{RESULTADOS E DISCUSSÃO}

O ponto localizado na entrada do reservatório (P01), com interface entre o ambiente lótico e lêntico, apresentou menores valores de abundância relativa de cianobactérias quando comparados com os demais. Em 19 coletas variou de ausência a 26,58\%. A influência do ambiente lótico neste local pode explicar os valores reduzidos de abundância relativa na maioria das amostragens, uma vez que águas com maior turbulência limitam o desenvolvimento destes organismos (Tabela 1).

Tabela 1. Abundância relativa de Cyanobacteria (\%) nos pontos amostrais estudados.

\begin{tabular}{lcccc}
\hline \multicolumn{1}{c}{$\begin{array}{c}\text { Mês de } \\
\text { amostragem }\end{array}$} & \multicolumn{4}{c}{ Pontos amostrais } \\
\cline { 2 - 5 } & P01 & P02 & P03 & P04 \\
\hline Julho/2009 & 6,25 & 12,5 & 4,73 & 5,83 \\
Agosto/2009 & 3,15 & 6,76 & 1,67 & 3,2 \\
Setembro/2009 & 18,09 & 9,33 & 4,81 & 1,93 \\
Dezembro/2009 & 15,97 & 4,88 & 3,43 & 11,41 \\
Março/2010 & 5,79 & 23,98 & 13,16 & 3,51 \\
Junho/2010 & 8,81 & 19,53 & 3,6 & 9,15 \\
Setembro/2010 & Ausente & 15,17 & 20,12 & 9,7 \\
Dezembro/2010 & 11,51 & 5,25 & 31,17 & 36,39 \\
Março/2011 & 18,03 & 20,54 & 60,56 & 61,79 \\
Junho/2011 & 24,61 & 25,68 & 50,34 & 43,42 \\
Setembro/2011 & 5,48 & 28,65 & 26,03 & 29,65 \\
Janeiro/2012 & 7,34 & 14,11 & 52,99 & 51,59 \\
Agosto/2012 & 56,6 & 7,87 & 72,56 & 1,54 \\
Janeiro/2013 & 11,45 & 6,28 & 25,29 & 24,14 \\
Março/2013 & 11,45 & 6,28 & 25,29 & 24,14 \\
Junho/2013 & 17,59 & 40 & 57,59 & 32,01 \\
Setembro/2013 & 26,58 & 48,56 & 89,05 & 83,34 \\
Dezembro/2013 & 14,29 & 27,24 & 63,37 & 69,95 \\
Junho/2014 & 2,97 & 45,78 & 27,76 & 50,09 \\
\hline
\end{tabular}

Fonte: Dados da pesquisa (2015)

$\mathrm{Na}$ região central do reservatório (P02) os valores de abundância relativa foram mais elevados que em P01, e menores que $\mathrm{P} 03$ e $\mathrm{P} 04$ e variaram de $4,88 \%$ a $48,56 \%$ nos períodos amostrais. 
O ponto localizado a montante do barramento foi o que apresentou os maiores valores de abundância relativa, variando de $1,67 \%$ a $89,05 \%$. Baixos valores de abundância relativa neste ponto podem ser atribuídos ao período do enchimento do reservatório, uma vez que ainda não havia condições para o estabelecimento de cianobactérias neste local. Com a estabilização da coluna d'água, as densidades de cianobactérias foram aumentando e apresentaram dominância em 7 episódios amostrais. A localização deste ponto propicia o crescimento destes organismos, uma vez que além de congregar os eventos ocorridos na bacia hidrográfica em relação aos nutrientes, apresenta maior profundidade e estabilidade da coluna d'água. A proliferação de algas e cianobactérias acontece, na maioria dos casos, devido ao enriquecimento artificial por nutrientes, principalmente fosfatados e nitrogenados [15].

O P04 está localizado a jusante do barramento e recebe influência direta do ponto a montante e por isso também apresentou valores elevados de abundância relativa de cianobactérias que variaram de $1,54 \%$ a $83,34 \%$.

Em 2009, ano de enchimento do reservatório, as cianobactérias foram pouco representativas no fitoplâncton total, tendência que se estabeleceu até setembro de 2010, onde os valores de abundância relativa começaram a se elevar (em torno de
$30,00 \%)$ principalmente nos pontos a montante (P03) e jusante do reservatório (P04). A partir de dezembro de 2010, foram realizadas 12 coletas e dentre elas o reservatório apresentou 9 episódios de dominância de cianobactérias (valores acima de $50,00 \%)$. Sob determinadas condições ambientais as cianobactérias podem se tornar a parcela dominante do fitoplâncton de lagos, reservatórios e rios, formando muitas vezes florações. $\mathrm{O}$ enriquecimento das águas com nutrientes provenientes de esgotos urbanos, efluentes provenientes de atividades agropastoris e industriais, principalmente nitrogênio e fósforo, e considerado a principal causada ocorrência de florações de cianobactérias [4].

A partir de dezembro de 2010, após o período de enchimento e estabilização do reservatório, as condições climáticas e hídricas da $\mathrm{PCH}$ Porto Franco se mostram propícias à predominância de cianobactérias. Devido às características climáticas da região, o reservatório da PCH Porto Franco apresentou durante o estudo, período de chuva e estiagem bem distintos, ocorrendo de outubro a março e maio a setembro respectivamente. Observou-se, porém a inexistência de um padrão de dominância destes organismos relacionado à sazonalidade. A dominância de cianobactérias ocorreu tanto no período seco como no chuvoso (Figura 2).

Figura 2. Valores de IET (médio) e abundância relativa (\%) dos pontos amostrais

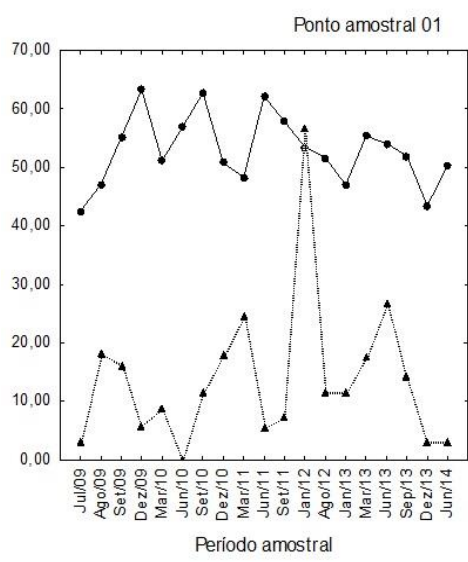

- IET (Médio)

- Abundância relativa (\%)

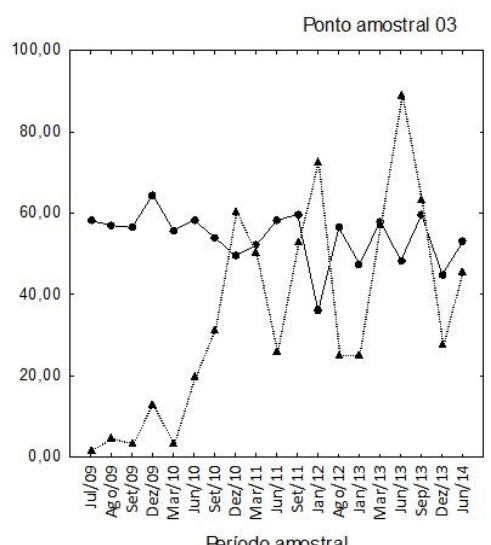

Periodo amostral
- IET (Médio)

- Abundância relativa (\%)

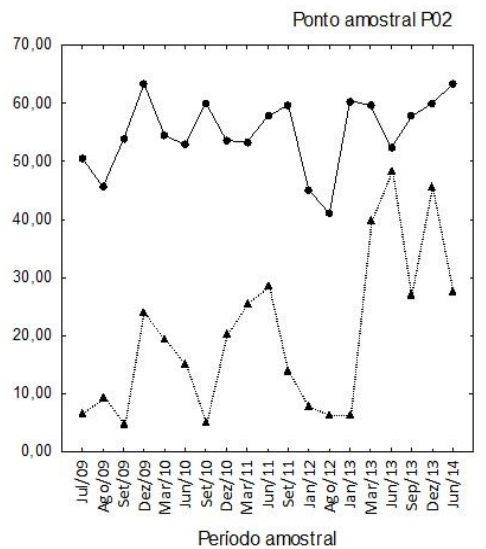

- IET (Médio) —. Abundância relativa (\%)

Ponto amostral 04

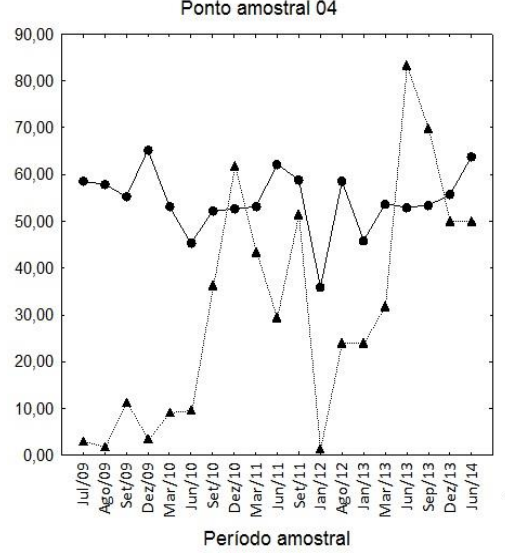

- IET (Médio)

- Abundância relativa (\%) 
Os episódios de dominância de cianobactérias estiveram relacionados às altas densidades de Planktolyngbya limnetica e $C$ ylindrospermopsis raciborskii, espécies fitoplanctônicas muito comuns em reservatórios brasileiros. C. raciborskii tem sido registrada como espécie dependente de certa estabilidade física da coluna de água e que se desenvolve quase que exclusivamente em águas com temperatura acima de $20^{\circ} \mathrm{C}$, característica comumente encontrada no reservatório da $\mathrm{PCH}$ Porto Franco. O sucesso da espécie invasora $C$. raciborskii, pode ser atribuído a fatores como: habilidade de flutuar; baixo requerimento de luz; alta taxa de assimilação do amônio; capacidade de fixar o nitrogênio atmosférico; alta afinidade pelo fósforo e grande capacidade de estoque deste elemento; e resistência a predação pelo zooplâncton $[4,16,17]$. P. limnetica tem sido a associada a ambientes túrbidos e misturados sendo tolerantes a baixas intensidades de luz [18].

\section{Planktolyngbya}

\section{limnetica}

\section{e} Cylindrospermopsis raciborskii são consideradas espécies potencialmente tóxicas relacionadas à produção de hepatotoxinas e neurotoxinas. A mesma espécie de $C$. raciborskii está relacionada à produção de diferentes toxinas (cilindrospermopsina e saxitoxina) em locais distintos do planeta. De acordo com suas estruturas químicas, as cianotoxinas podem ser incluídas em três grandes grupos: os peptídeos cíclicos, os alcaloides e os lipopolissacarídeos. Entretanto, por suas ações farmacológicas, as duas principais classes de cianotoxinas até agora caracterizadas são as neurotoxinas e hepatotoxinas. Nem todas as florações de cianobactérias são tóxicas e algumas podem ser tóxicas durante apenas um período do ano, do mês ou da semana [4].

$\mathrm{O}$ aumento das densidades de cianobactérias é um bom indicador da qualidade da água. $\mathrm{O}$ reservatório da $\mathrm{PCH}$ Porto Franco está constantemente sujeito a alta incidência luminosa e altas temperaturas do ar o que somados as condições predominantemente mesotróficas do reservatório, o tornou favorável ao crescimento destes organismos.

A avaliação dos dados mostra que, os valores de clorofila $a$ e fósforo total apresentaram uma ampla gama de variação. As concentrações encontradas do parâmetro fósforo total para as águas superficiais no reservatório da $\mathrm{PCH}$ Porto Franco, oscilaram entre o limite de detecção do método $(0,002)$ e $0,540 \mathrm{mg} \cdot \mathrm{L}^{-1}$. Com destaque, para os dados obtidos durante a amostragem de dezembro de 2009 que apresentaram altas concentrações do parâmetro em todos os pontos amostrais.
Dos 76 dados obtidos de fósforo total, $63,16 \% \quad(\mathrm{n}=48) \quad$ apresentaram concentrações inferiores ou iguais a $0,050 \mathrm{mg} \cdot \mathrm{L}^{-1}$. Segundo metodologia proposta por LAMPARRELI (2004), amostras com valores superiores a $0,052 \mathrm{mg} . \mathrm{L}^{-1}$ para o parâmetro fósforo total são considerados ambientes com estado de trofia, eutrófico.

Dos 76 dados de clorofila $a$ analisados $83,34 \% \quad(\mathrm{n}=60 \quad$ amostras $) \quad$ apresentaram concentrações inferiores ou iguais a $11,03 \mu \mathrm{g} . \mathrm{L}^{-1}$, limite estabelecido por Lamparreli [14] para ambientes eutrofizados. As concentrações de clorofila $a$ variaram de 0,15 a $28,36 \mu \mathrm{g} . \mathrm{L}^{-1}$ no período amostral, ou seja, entre as classes ultraoligotrófico e eutrófico. As maiores concentrações foram observadas no ponto amostral P02, com valor médio de $6,87 \mu \mathrm{g} \cdot \mathrm{L}^{-1}$.

O ponto localizado na entrada do reservatório (P01), com interface entre o ambiente lótico e lêntico apresentou predominância do estado "oligotrófico", durante o período observado. Em $42,10 \%$ das coletas nesse ponto amostral, o mesmo foi considerado "oligotrófico", seguido de 26,32\% das amostras sendo consideradas "mesotróficas", $15,80 \%$ das amostras classificadas como estado trófico "ultraoligotrófico", $10,52 \%$ como eutrófico e 5,26\% "superteutrófico". Em dezembro de 2009, a classificação foi "supereutrófico", justificado pelo incremento observado para o PT em todos os pontos amostrais. Sendo assim, o ponto amostral 01 apresentou seus valores de IETm oscilando entre 43,41 e 63,32 . Esse resultado mostra um ponto de amostragem com baixas concentrações de nutrientes e produtividade primária, com eventos esporádicos de condições eutróficas. Pode-se destacar, a contínua diminuição do grau de trofia a partir de setembro de 2011.

Nota-se também, a ocorrência de apenas um evento de dominância de cianobactérias nesse ponto amostral, ocorrido em janeiro de 2012, com abundância relativa de 56,60 \% e com densidade total de 1908 ind.ml (Tabela 2).

Através do cálculo do índice do estado trófico segundo Lamparelli [14], a estação amostral localizada na parte central do reservatório, P02, apresentou uma ampla gama de variação durante o período amostral. Os valores de IET médio oscilaram de 41,00 em agosto de 2012 a 63,33 em dezembro de 2009. Em 42,11\% das amostras coletadas nessa estação amostral, o ponto foi classificado como "mesotrófico", em 26,31\% como "eutrófico", em 15,79\% como "ultraoligotrófico", em 10,53\% como supereutrófico e em 5,26\% como "oligotrófico". Foi observada uma leve deteorização da qualidade da água do P01 para o P02, uma vez 
que essa estação amostral foi classificada como "mesotrófica" com uma incidência maior de eventos, que demonstram condições de elevado enriquecimento de nutrientes e alta produtividade planctônica ("eutrófico" e "supereutrófico") corroborando com o incremento da densidade total (ind. $\mathrm{mL}^{-1}$ ) de fitoplâncton. Em janeiro de 2013 foi observado um acréscimo da biomassa fittoplanctônica com densidade total de 3591 ind. $\mathrm{mL}^{-1}$, a maior observada durante o período amostral. $\mathrm{O}$ estado trófico, durante essa amostragem, foi classificado como "eutrófico". É válido ressaltar que mesmo com essas condições não tivemos dominância de Cianobactérias durante as amostragens.

Tabela 2. Densidade total (ind. $\mathrm{mL}^{-1}$ ) nos pontos amostrais estudados.

\begin{tabular}{lcccc}
\hline \multicolumn{1}{c}{$\begin{array}{c}\text { Mês de } \\
\text { amostragem }\end{array}$} & \multicolumn{4}{c}{ Pontos amostrais } \\
\cline { 2 - 5 } & P01 & P02 & P03 & P04 \\
\hline Julho/2009 & 160 & 180 & 1290 & 1046 \\
Agosto/2009 & 2700 & 148 & 1438 & 1592 \\
Setembro/2009 & 188 & 1158 & 1415 & 2716 \\
Dezembro/2009 & 263 & 574 & 932 & 1367 \\
Março/2010 & 259 & 342 & 585 & 1169 \\
Junho/2010 & 227 & 214 & 389 & 153 \\
Setembro/2010 & 180 & 323 & 323 & 330 \\
Dezembro/2010 & 305 & 305 & 523 & 404 \\
Março/2011 & 172 & 331 & 839 & 649 \\
Junho/2011 & 65 & 222 & 582 & 357 \\
Setembro/2011 & 146 & 171 & 584 & 344 \\
Janeiro/2012 & 109 & 163 & 1172 & 628 \\
Agosto/2012 & 1908 & 178 & 2602 & 2467 \\
Janeiro/2013 & 166 & 446 & 550 & 377 \\
Março/2013 & 370 & 3591 & 2182 & 270 \\
Junho/2013 & 91 & 610 & 1061 & 528 \\
Setembro/2013 & 521 & 521 & 1918 & 1765 \\
Dezembro/2013 & 56 & 246 & 1187 & 569 \\
Junho/2014 & 472 & 1029 & 890 & 533 \\
\hline Fonte: Elaborado pelo aut & & & \\
\hline
\end{tabular}

Fonte: Elaborado pelo autor

A estação amostral localizada em frente ao barramento da PCH de Porto Franco, P03, apresentou os maiores valores de densidade total de fitoplâncton do estudo. O IET médio exibiu uma oscilação de 35,94 a 59,57. A predominância de estado trófico desse ponto amostral foi "mesotrófico", fato constatado em 57,90\% das coletas realizadas, seguida da classificação "ultraoligotrófico" em 21,05\%, "eutrófico" em $10,53 \%$, 5,26\% "oligotrófico" e em 5,26\% "supereutrófico. Esse ponto amostral teve a maior abundância relativa de cianobactéria do estudo, em junho de 2013, 89,05\% da comunidade fitoplanctônica.

Segundo Lamparelli [14] para avaliação do grau de limitação da produtividade do fitopâncton, são comparadas as classificações obtidas entre o IET $(\mathrm{Cl})$ e o IET (P). Quando os dois índices classificam os ambientes na mesma classe trófica, o grau de limitação é considerado "normal". Quando a classificação através do índice do fósforo classifica o ambiente em classe superior à obtida através das concentrações de clorofila $a$, indicando que há algum fator limitante que reduz a produtividade das algas o grau de limitação é considerado "alto". No caso inverso, quando as concentrações de clorofila $a$ resultam em uma classificação superior à obtida pelo IET $(\mathrm{P})$, o grau de limitação é considerado "baixo", existindo condições favoráveis para a produtividade primária, considerando os nutrientes disponíveis. $\mathrm{O}$ ponto 03 apresentou $47,37 \%$ das amostras com grau de limitação "normal", 42,11\% com grau de limitação "alto" e 10,52\% com grau de limitação "baixo".

A estação amostral localizada à jusante da PCH de Porto Franco, P04, apresentou o IET médio oscilando de 35,94 a 65,25. A predominância de estado trófico desse ponto amostral foi "mesotrófico", sendo que em 68,42\% das coletas realizadas apresentaram essa classificação, seguido do estado "ultraoligotrófico" em 15,79\%, "supereutrófico" em 10,53\% das amostras coletadas e em 5,26\% "eutrófico". Os índices de eutrofização encontrados no P04 mantiveram-se linearmente durante grande parte do experimento, porém com a ocorrência de dominância de Cianobactérias em dezembro/2010, setembro/2011, junho/2013, setembro/2013, dezembro/2013 e junho/2014. Em relação à densidade total fitoplanctônica podemos observar um padrão de distribuição, com valores acima de 1.110 ind. $\mathrm{mL}^{-1}$ durante os meses iniciais do processo de estabilização do reservatório (julho a dezembro de 2009), um posterior declínio a partir de março de 2010 com densidades abaixo dos 700 ind. $\mathrm{mL}^{-1}$, com exceção da campanha de janeiro de 2012 (2.467 ind.mL $\left.{ }^{-1}\right)$ e junho de 2013 (1.765 ind. $\left.\mathrm{mL}^{-1}\right)$.

\section{CONCLUSÃO}

$\mathrm{O}$ reservatório da $\mathrm{PCH}$ Porto Franco na sua fase de enchimento e no período logo posterior (julho a setembro de 2009) apresenta condições de trofia que variaram de ultraoligotrófico a mesotrófico.

Em dezembro de 2009 ocorreu um evento estocástico, onde o reservatório apresenta altas concentrações de nutrientes e condições supereutróficas em todos os pontos. $\mathrm{Na}$ 
amostragem posterior, março de 2010, as condições voltaram à mesotrofia com execeção do ponto localizado na entrada do reservatório, considerado oligotrófico.

As cianobactérias ocorreram em todos os pontos monitorados e foram representadas por vários táxons potencialmente tóxicos, como Cylindrospermopsis raciborski e Planktolyngbya limnetica.

A dominância de Cyanobacteria foi associada às condições mesotróficas, eutróficas e supereutróficas que ocorreram especialmente nos pontos a montante e a jusante do barramento, principalmente a partir de dezembro de 2010, quando o reservatório já estava em processo de estabilização.

O predomínio do ambiente lêntico, disponibilidade de radiação subaquática, elevadas temperaturas da água durante o ano, bem como a disponibilidade de nutrientes demonstrados pelo IET são condições que estimulam a fotossíntese e a multiplicação das cianobactérias e determinaram o seu expressivo desenvolvimento no reservatório da PCH Porto Franco.

\section{AGRADECIMENTO}

A FAPTO pelo financiamento deste trabalho.

\section{CONTRIBUIÇÃO DOS AUTORES}

1. Condução e avaliação do experimento, análises estatísticas e elaboração do artigo:

$\mathrm{Dr}^{\mathrm{a}}$. Anelise Kappes Marques

Dayane Juliate Barros

2. Planejamento, orientação e revisão final do artigo:

Dra ${ }^{\mathrm{a}}$ Paula Benevides de Morais

\section{REFERÊNCIAS}

[1]. CARDOSO O. R.; ROCHA N. S.; XAVIER R. A.; VALDUGA, E. T.; DISCONZI G. S.; RADTKE L.; CRUZ, R. C. Análise de fragilidade ambiental na bacia do rio Pardo - RS, frente à instalação de pequenas centrais hidrelétricas ( $\mathrm{PCHs}$ ). Revista Brasileira de Recursos Hídricos, v.20, n.2, p.507522, 2015

[2]. VASCONCELOS, J.F.; BARBOSA, J. E. L.; DINIZ, C. R.; CEBALLOS, B. S. O. Cianobactérias em reservatórios do Estado da Paraíba: ocorrência, toxicidade e fatores reguladores. Boletim da Sociedade Brasileira de Limnologia, v. 39, n. 2, p. 1-20. 2011.

[3]. ESTEVES, F. A. Fundamentos de limnologia. Rio de Janeiro, Interciência/FINEP, 2011, 826 p

[4]. MOLICA, R.; AZEVEDO, S. Ecofisiologia de cianobactérias produtoras de cianotoxinas. Oecologia Brasiliensis, n.13, v. 2, p. 229-246, 2009.

[5]. CORDEIRO, E. M. S.; ROCHA, F. N. S.; PEQUENO, M. N. C.; BUARQUE, H. L. B.; GOMES, R. B. Avaliação comparativa dos índices de estado trófico das lagoas do Opaia e da Sapiranga. Fortaleza-Ce, IX ENCONTRO DE PESQUISA E PÓS-GRADUAÇÃO, IX ENCONTRO DE INICIAÇÃO CIENTIFICA, III SIMPÓSIO DE INOVAÇÃO TECNOLÓGICA, Fortaleza, 2009.

[6]. FIA, R.; MATOS, T. A.; CORADI, P. C.; RAMIREZ, O. P. Estado trófico da água na bacia hidrográfica da Lagoa Mirim, RS, Brasil. Revista
Ambiente e Água, v.4, n.1, 2009. DOI:10.4136/ambi.agua.78

[7]. BARROS, E. F. S.; M. C. H.; SOARES L. A.; SIQUEIRA E. Q.; PINHEIRO R. C. D. Influência do regime hidrológico sobre os parâmetros de qualidade das águas no rio Palmeiras, TO. XIX Simpósio Brasileiro de Recursos Hídricos. 2011.

[8]. BICUDO, C.E.; MENEZES, M. Gêneros de algas continentais do Brasil: chave para identificação e descrições. 2a ed., Rima. São Carlos, 2006. 502p.

[9]. APHA (American Public Health Association). Standard methods for the examination of water and wastewater. 21. ed. Washington APHA/WEF/AWWA, 2005

[10]. LUND, J. W. G. E; KIPLING, C.; LE CREN, E. D.. The inverted microscope method of estimating algal number and the statistical basis of estimating by counting. Hydrobiologia, n. 11, p. 143-170, 1958.

[11]. LOBO, E.; LEIGHTON, G. Estructuras comunitárias de las fitocenosis planctonicas de los sistemas de desembocaduras de rios y esteros de la zona central de Chile. Revista de Biologia Marina y Oceanografia, v.22, p.1-29, 1986.

[12]. ODUM, E. P. Ecologia. Trad. R. I. Rios. 1. ed. Rio de Janeiro: Interamericana, 1983.

[13]. WOOD, L. W. Chloroform-Methanol Extraction of Chlorophyll a. Canadian Journal of Fisheries and Aquatic Sciences, n. 42, p. 38- 43, 1985. DOI:10.1139/f85-005 
[14]. LAMPARELLI, M. C. (2004). Grau de Trofia em Corpos D'Água do Estado de São Paulo: Avaliação dos Métodos de Monitoramento. Tese (Doutorado) - Instituto de Biociências, Universidade de São Paulo, São Paulo - SP, 238 p

[15]. . VERAART, A. J.; ROMAN, Í, A. M.; TORNES, E.; SABATER, S. Algal response to nutriente enrichment in forested oligotrophic stream. Journal of Phycology, v. 44, p. 564-572, 2008. DOI:10.1111/j.1529-8817.2008.00503.x

[16]. BONILLA, S.; AUBRIOT, L.; SOARES, M. C. S.; GONZÁLEZ-PIANA, M.; FABRE, A.; HUSZAR, V. L. M.; LÜRLING, M.; ANTONIADES, D.; PADISÁK, J.; KRUK, C. What drives the distribution of the bloom-forming cyanobacteria Planktothrix agardhii and Cylindrospermopsis raciborskii? FEMS Microbiology Ecology, v. 79, p.594-607, 2012. DOI:10.1111/j.15746941.2011.01242.x

[17]. TUNDISI，J. G.; MATSUMURA-TUNDISI，T.; TUNDISI, J. E. M.; BLANCO, F. P.; ABE, D. S.; CONTRI CAMPANELLI, L.; SIDAGIS GALLI, G.; SILVA, V. T.; LIMA, C. P. P. A bloom of cyanobacteria (Cylindrospermopsis raciborskii) in UHE Carlos Botelho (Lobo/Broa) reservoir: a consequence of global change? Brazilian Journal of Biology, São Carlos, v. 75, n. 2, p. 507-508, 2015. DOI:10.1590/1519-6984.24914

[18]. .PADISAK, J. L.; CROSETTI, L. O.; NASELLI FLORES, L. Use e misuse in the application of the phytoplankton functional classification: a critical review with updates. Hydrobiologia, n. 621, p. 119, 2009. DOI:10.1007/s10750-008-9645-0 